expression-in the interval between November 30,1875 , when he proposed it should be buried, and the time of his first subsequent attack upon me.

It is untrue that during this interval, or at any other time, I gave my "public attestation to the spiritualistic genuineness of what had been proved to be a most barefaced imposture."

It is untrue that I gave Eva Fay a letter, speaking of the "Spiritualistic nature of her manifestations," and referring to "Fellows of the Royal Society."

It is untrue that Eva Fay "returned to the United States carrying with her" such a letter.

It is untrue that "this letter was published in facsimile in American newspapers."

When Dr. Carpenter limits himself to definite statements, my task is not difficult. It is, however, less easy to answer a rumour of something which somebody told Dr. Carpenter I privately admitted.

"It has been rumoured," says Dc. Carpenter, in Fraser's Magazine, "that Mr. Crookes has privately admitted that some of his 'mediums,' when they could not evoke the 'manifestations' by fair means, have done so by foul."

I admit that such a rumour respecting Eva Fay was circulated in the United States, and a Boston gentleman wrote and asked me if there was any truth in this statement. I replied as follows under date November $8,1875:-$

"In reply to your favour of October 25, which I have received this morning, I beg to state that no one has any authority from me to state that I have any doubts of Mrs. Fay's mediumship. The published accounts of the test séances which took place at my house are the best evidence which I can give of my belief in Mrs. Fay's powers. I should be sorry to find that any such rumours as you mention should injure Mrs. Fay, whom I always found most ready to submit to any conditions I thought fit to propose."

Considering that this was a private letter from one gentleman to another, written currente calamo without any thought of subsequent. publication, few of your readers, I believe, will see much harm in it. Not being a ware that private communications were less sacred in America than in England, I was certainly surprised one morning to receive a copy of an American newspaper containing a facsimite of this private letter.

It will be observed that this letter is dated November $8, \mathrm{I} 875$, whereas the "bury-the-hatchet" episode took place on November 30,1875 ; this therefore cannot be the letter which convicts me of attesting to a "barefaced imposture "subsequent to November 30 .

Moreover, this letter does not contain the words "Spiritualistic nature of her manifestations." Neither does it allude to "Fellows of the Royai Society." Nor did Eva Fay return to "the United States, carrying with her this letter." Nor was it even addressed to Eva Fay. It is then impossible that this can be the letter to which Dr. Carpenter refers, and I demand that he prove the truth of his allegation by producing a copy of the "American newspapers" containing a facsimile of a letter written by me answering his description, containing the words which he professes to quote from it, and justifying his defamatory remarks.

In your issue of last week (p. 26) Dr. Carpenter says nothing about this facsinile letter, but lays stress on an article written by me ten months previously. Does he seriously mean that the publication in March, 1875, of an account of some test experiments is a breach on my part of his "bury-the-hatchet" offer made the following November?

I have evidently been labouring under a misapprehension as to what Dr. Carpenter meant when he proposed to "bury the hatchet." I supposed he intended to cease misrepresenting my views and falsifying my experiments at his public lectures, and never afterwards to repeat such calumnies on my scientific position as he had anonymously contributed to the Quarterly Review for October, 187r. It seems, however, that Dr. Carpenter really meant that I was no longer to go poaching on his own special preserve, and was to abstain for the rest of my life from writing even a private letter on a subject which he has investigated for more than thirty years, and about which he is now writing and lecturing with redoubled vigour.

Dr. Carpenter refers to an offer made in May, 1875, "by Eva Fay's manager, that for an adequate sum of money the 'medium' should expose the whole affair," and he vouches for its truth by saying he has seen "copies of the letters." I can supply, not copies, but original letters. I have before me letters from Eva Fay, dated Birmingham, May, 1875 , speaking bitterly of the temptations and persecution to which she was being subjected to induce her to join in the scheme, to which she was no party.

But how, may I ask, does an abortive conspiracy to complicate " six big guns" prove that my "scientific tests" - which with all deference to Dr. Carpenter's "good authority" can not be evaded by a "dodge"-were useless, and that in spite of them Eva Fay cheated me?

I am weary of protesting against the imputation which Dr. Carpenter conveys in the words "scientific advocates of the system." I emphatically deny that I have ever advocated any "system" in connection with the phenomena ascribed to spiritualism. I have never for one moment doubted that this name has covered an enormous mass of fraud and trickery ; but being convinced that amidst all this falsehood-which it is Dr. Carpenter's mission to denounce in the most fervid eloquence at command-there was a solid nucleus of fact, and believing that every unrecognised fact is a reproach to science, and every uninvestigated phenomenon is a probable mine of discovery, I considered myself not merely entitled, but almost bound in scientific honour, to attempt the solution of the question. My attempt to bring the so-called supernatural within the realm of fact, to turn the light of science on a problem that required investigation, has exposed me to many misrepresentations, but especially to the ire of Dr. Carpenter, who never tires of repeating every idle tale from hearsay evidence. I look back to the days of the alchemists, and find the very same kind of fraud, mysticism, and trickery, differing but little from the impostures of the present day. But then, as now, there were a few earnest students who detected the germs of truth amidst the ravings and juggleries of the gold makers ; they cherished these germs, and although the Dr. Caripenter of that period would doubtless have denounced those students as "scientific advocates of the system" of alchemy, and felt it his duty to "undermine" their reputations, they persevered tbrough calumny and ridicule, and thereby laid the foundations of our modern science of chemistry.

The readers of NATURE have now before them ample illustration of the falsity of the accusations with which I have been persecuted for so many years. A calumny once born, said the Great Napoleon, can never be killed. I have, however, done my utmost to prove the groundlessness of the very serious charges Dr. Carpenter has brought against me, down to the grave indictments in your issue of last week (p. 26). There is not a single charge which Dr. Carpenter has ever brought against me that I am unable to answer with like comp'eteness; and, judging from long experience, I venture to say that any future charges he may bring will be equally unfounded. But I cannot, out of regard for your readers, to say nothing of the sacrifice of time, continue to defend myself from every petty accusation; and unless really forced by some imputation too serious to pass over, this must be my last letter on a subject which to me involves painfully too much self-reference. I have been constrained, in self-defence, to speak in somewhat downright fashion, but Dr. Carpenter's industrious misconstruction has drawn this protest from me Misstatements expressed in a few lines may rerquire pages to refute them. A calumny which takes a minute to write may demand days to answer. Memories of half-forgotten occurrences have to be revived, conversations recalled, old letters hunted out, journals exhumed, and, in fact, as much time and trouble expended as if getting up evidence for an important legal trial. So great a tax for so trivial a purpose is monstrous in its disproportion, and I can waste on this fruitless discussion no more precious time - time stolen from my physical work in the laboratory, already too much curtailed by the pressure of outward business.

November Io

William Crookes

ThE latter half of Dr. Carpenter's letter in last week's NATURE (p. 26) consists of almost verbatim extracts from his article in this month's Fraser. I beg to refer your readers to a reply to Dr. Carpenter's attack, and a full exposure of his false accusations agatnst Mr. Crookes and myself, which will appear in the next issue of that magazine. They will then see who has been led by "prepossession" to adopt "methods which are thoroughly un scientific," and whose are "the statements which ought to be rejected as completely untrustworthy."

ALFRED R. WALlaCE

\section{Experiment on Fluid Films}

I AM experimenting on the optical phenomena exhibited by thin fluid films in a state of vibration, and have just obtained 